\title{
Quality Management Interconnection of Universitas Pasifik Morotai
}

\author{
Irawati Sabban \\ Universitas Pasifik Morotai \\ e-mail: irawatisabban@gmail.com \\ Irfan Hi. Abd Rahman \\ Universitas Pasifik Morotai \\ e-mail: djoeangmrt@gmail.com
}

\begin{abstract}
The purpose of this study is to examine how interconnection practices in management, policy, planning and leadership studies are focused on quality management practices set out in the SPMI at the Universitas Pasifik Morotai (UNIPAS) Quality Assurance Institute (LPM). The research method used in this study is qualitative research. Data needed in this study are primary data and secondary data. The primary data source is the Chairperson of the Universitas Pasifik Morotai (UNIPAS) Quality Assurance Institute as Quality Control and Supervision at the Universitas Pasifik Morotai (UNIPAS). Quality documents as secondary data sources. Quality Assurance, is a proof of Universitas Pasifik Morotai's commitment to develop a quality culture. The SPMI policy is a written documentation containing an outline of an explanation for understanding, designing, and implementing SPMI in the administration of higher education services to the community so that quality culture is realized. The quality management process at the Universitas Pasifik Morotai (UNIPAS) shows that the four elements of the interconnection of management studies, policy, leadership and planning have a very strong link in the administration of higher education activities at the Universitas Pasifik Morotai (UNIPAS).
\end{abstract}

Keywords: Interconnection, Management, Policy, Planning, Leadership

\section{INTRODUCTION}

Referring to Law Number 20 of 2003 concerning the National Education System and Government Regulation No. 19 of 2005 concerning National Education Standards for implementing quality assurance in tertiary institutions is a mandatory activity. Higher education quality assurance is an obligation that cannot be ignored anymore by universities. This is caused by various challenges of higher education including: (1) the influence of global interventions and education liberalization; (2) national macro issues such as: economic, political, moral and cultural; (3) globalization, openness, democracy, thinking rationalization, competitive culture; (4) the role of tertiary institutions in forming civil society; (5) the low competitiveness of graduates at the national / international level; and so forth, in the face of an increasingly dynamic world development, universities as one of the agents of change in the quality of human resources play a very strategic role. Referring to these conditions, Universitas Pasifik Morotai (UNIPAS) feels the need to implement a quality assurance system that is systematic, integrated, and sustainable. Universitas Pasifik Morotai (UNIPAS) Quality 
Assurance Institute (LPM) was formed to ensure the sustainability of the University of the Pacific as a tangible contribution to improving the nation's competitiveness. In terms of institutions, quality assurance institutions have also been formed starting from the University level called the Quality Assurance Institution (LPM), at the Faculty level there is a Faculty Quality Assurance Unit (UPMF) and at the study program level there is a Study Program Quality Assurance Sub Unit (SUPMP)

The written policy document is intended as:

a. a means to communicate to all stakeholders about SPMI applicable within the Morotai Pacific university environment

b. the basis and direction in determining all standards and manuals or procedures in SPMI, as well as in implementing and improving the quality of SPMI

c. authentic proof that the Universitas Pasifik Morotai (UNIPAS) has owned and implemented SPMI as required according to statutory regulations.

Therefore, the preparation of the SPMI Universitas Pasifik Morotai (UNIPAS) policy document legally is based on Law No. 12 of 2012 concerning Higher Education and Permenristekdikti no 44 of 2015 concerning National Standards of Higher Education. The framework for the contents of this policy was prepared using the Guidelines for Higher Education Quality Assurance System (Kemensristekdikti, 2016).

Based on the explanation above, the focus of this study will examine how interconnection practices in management, policy, planning and leadership studies are focused on quality management practices as outlined in SPMI at the Universitas Pasifik Morotai (UNIPAS) Quality Assurance Institute (LPM).

\section{RESEARCH METHODS}

The research method used in this study is qualitative research. Qualitative research is fundamental and tentative depending on the phenomenon of the field. In addition, this study is the words of a limited number of key individuals

\section{Data and Data Sources}

Data is very important in uncovering a problem or answering a problem that has been previously formulated. According to Moleong (2011: 157) that in qualitative research the words and actions of the people observed or interviewed are the main data sources. Data needed in this study are primary data and secondary data. The primary data source is the Chairperson of the Universitas Pasifik Morotai (UNIPAS) Quality Assurance Institute as Quality Control and Supervision at the Universitas Pasifik Morotai (UNIPAS). Quality documents as secondary data sources.

\section{Data collection technique}

The technique used in this research is in-depth interview technique about:

Policy formulation, leadership, planning and management, of course, are at the heart of all educational visions. Furthermore, the theoretical interconecction discussion on the four pillars of leadership, management, planning and policy.

\section{Leadership}

Bass \& Bass (2011) in Usman (2014: 56) defines leadership as the interaction of two or more people in a structured or re-structured group of members' perceptions and expectations. The two people are leaders with their subordinates. Both or more equate perceptions and expectations in order to have the same mindset, attitude patterns, and patterns in meeting shared expectations. From the above definition we can see the similarity in the role of leadership is the relationship between two or more people, this relationship is demonstrated by 
interacting, communicating between two or more, how to influence. This means that there is an interconecction pattern in leadership

\section{Management}

In Tony Bush's book (2008) there are several definitions of experts including: Bolam (1999: 194) defines management education as 'an executive function to implement agreed policies'. He distinguishes management from leadership which 'at its core has responsibility for formulation. Sapre (2002: 102) states that 'management is a set of objective activities directed at the efficient and effective use of organizational resources to achieve organizational goals'. Glatter (1979: 16) argues that management studies relate to 'the internal operations of educational institutions, and also their relationship with their environment, namely the community in which they are located, which is formally their responsibility'

Bush (2008) links leadership with values or goals. while management is related to implementation or technical issues. Leadership and management need to be given the same position if schools and colleges will operate effectively and achieve their goals. Leadership and Management according to Bush cannot be separated from each other meaning they are interconnected so that the typologies of both are formulated in the following table;

Typology table for Tony Bush's management and leadership model (2008)

\begin{tabular}{|l|l|}
\hline Management Model & Leadership Model \\
\hline Formal & Managerial \\
\hline Collegial & $\begin{array}{l}\text { Partisipatif } \\
\text { Transformasional } \\
\text { Interpersonal }\end{array}$ \\
\hline Political & Transactional \\
\hline Subjective & Postmodern \\
\hline Ambiguous & Contingency \\
\hline Cultural & $\begin{array}{l}\text { Moral } \\
\text { Instructional }\end{array}$ \\
\hline
\end{tabular}

\section{Planing}

Planning according to Handoko (2003) includes (1) choosing or setting organizational goals, (2) determining the strategies, policies, projects, program procedures, methods, systems, budgets, and standards needed to achieve goals. According to Gamage \& Zahda (2009) "Planning is a process that precedes decision making" planning is decision making. Theories and concepts of planning according to Prof. Fakry on 27 February 2020 lecture "planning is part of studying and manipulating the future, the past is the product of the present, and the present is the product of the future. In planning there must be policies and strategies, because policies and strategies are implemented to achieve goals. Planning must reach the event or activity, a leader must have a strong imagination to build a vision

From this explanation we can know that in planning there are interventions, planning with policies, planning with management, and planning with leadership

4. Policy

In implementing the most important policy is communication, as expressed by Edwards III communication regarding how the policy is communicated to the organization. There are three things that require attention in this communication, 
namely the transmission of communication, the clarity of the policy to be communicated, and its consistency. The same thing was said by Prof. Fakry in his lecture that policy had grand strategies. Strategies are the right alternative way to avoid mistakes in describing policies

\section{Data Analysis Technique}

The validity and reliability test commonly used in qualitative research is the Triangulation technique. According to Moleong (2011) triangulation is a data validity checking technique that utilizes something else as a comparison of the data obtained. The triangulation technique used in this study is data triangulation, data source triangulation, method triangulation and researcher triangulation.

\section{FINDING AND DISCUSSION}

Management of SPMI Universitas Pasifik Morotai (UNIPAS)

Higher education is declared qualified if it is able to set and realize its vision through the implementation of its mission (deductive aspects) and meet the needs of stakeholders (inductive aspects), namely social needs (societal needs), needs of the world of work (industrial needs), and professional needs (professional needs). The quality of higher education is based on identity, vision, mission, goals, objectives, curriculum, human resources (lecturers and other education personnel), student affairs, learning processes, infrastructure and facilities, academic atmosphere, funding / finance, research and publications, service to the public, governance, governance / institutional management (institutional management), information systems, quality assurance systems, as well as graduates and alumni. To realize quality higher education, internally universities must implement a quality assurance system and externally will be evaluated by relevant external institutions.

Quality Assurance, is a proof of Universitas Pasifik Morotai (UNIPAS)'s commitment to develop a quality culture. The SPMI policy is a written documentation containing an outline of an explanation for understanding, designing, and implementing SPMI in the administration of higher education services to the community so that a quality culture is realized. The document contains an explanation of the background or reasons, objectives, strategies, principles, and direction of Universitas Pasifik Morotai (UNIPAS) to guarantee and improve quality in each of its activities. Because the Quality Assurance Management System (SPMI) is a written quality manual document that contains practical instructions on how, steps, or procedures on how SPMI in Universitas Pasifik Morotai (UNIPAS) is implemented, evaluated, and improved in quality by all work units in Universitas Pasifik Morotai (UNIPAS).

Based on the quality policy and quality manual, the document which is further developed is the Quality Standards in SPMI. Quality Standards in SPMI are written documents containing various criteria, measurements, benchmarks or specifications of all activities in conducting tertiary education in order to realize its vision and mission so that they can be assessed as quality in accordance with statutory provisions so as to satisfy internal and external stakeholders. Quality Standards in SPMI Universitas Pasifik Morotai (UNIPAS) refers to National Education Standards and other relevant standards. The quality standard consists of quality standards for the implementation of Tri Dharma Higher Education activities. 
The starting point in this research is the Management of the Implementation of SPMI Universitas Pasifik Morotai (UNIPAS) then integrated into leadership, policy, and planning. For complete information is as follows.

\section{Management}

Internal Quality Assurance Standards (SPMI) at the Universitas Pasifik Morotai (UNIPAS) are designed, implemented, and improved in continuous quality based on PPEPP (Planning, Implementation, Evaluation, Improvement) will produce kaizen or Continuous quality improvement of higher education quality. With the PPEPP management model, each unit within the university must periodically conduct a selfevaluation process to assess the performance of its own units using established standards and procedures. The results of the self-evaluation will be reported to the head of the unit, all staff in the unit concerned, and to the leadership of the university. On the results of self-evaluation unit leaders and university leaders will make decisions about the steps or actions that must be taken to improve and improve quality.

Implement SPMI with the PPEPP management model that requires each unit in the university to be open, cooperative, and ready to be audited or examined by a team of internal auditors who have received special training on SPMI audits. Audits conducted at the end of each academic year will be recorded and reported to the head of the unit and university, and then certain actions are taken based on the findings and recommendations of the auditor team. The results of the implementation of SPMI on the basis of the PPEPP model are the readiness of all study programs within the university to participate in the accreditation process or external quality assurance. If a plot is made, it is presented as shown below:

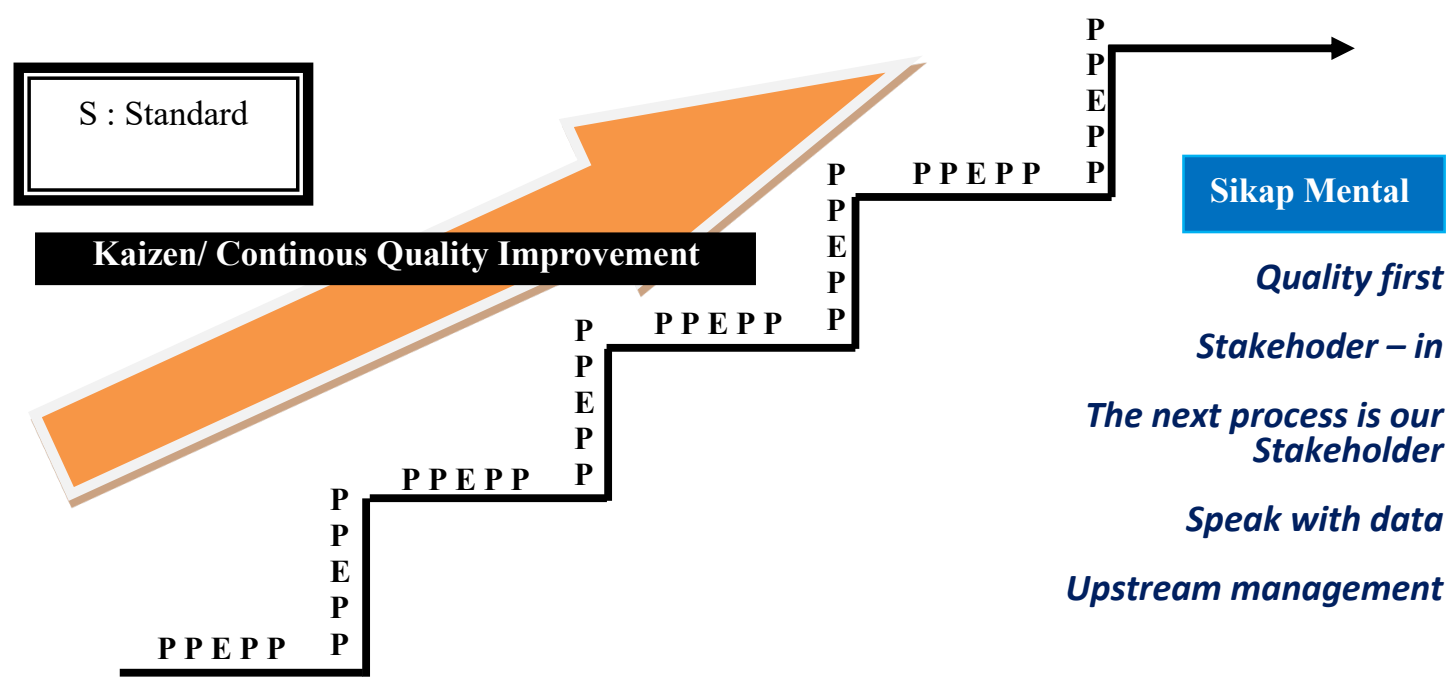

Figure 1. PPEPP Model

The above activities, which are cyclical in nature, involve internal monitoring and evaluation activities by authorized work units and external monitoring and evaluation, such as the accreditation of study programs and institutions by BAN / LAM PT. After the evaluation step is to take control steps. Control is a follow-up to the results obtained from the evaluation activities. This means that the follow-up can be done on the results of self-evaluation, internal audit, or on the results of accreditation. If the evaluation results show that the implementation of the standard content has been in accordance with what was planned so that the contents of the standard will be ensured to be 
fulfilled, the control measure is only in the form of efforts to ensure that positive things can continue to run as they should.

Conversely, if in the evaluation of the implementation of standards found errors, inaccuracies, deficiencies or weaknesses that can cause failure to achieve the contents of the standard or objectives / targets / plans, control measures must be taken. These control measures take the form of corrective or corrective actions to ensure compliance with orders / criteria / targets in the standard. There are several types of corrective actions as a follow-up to the evaluation results, ranging from holding a leadership meeting specifically discussing the results of the evaluation to carrying out certain corrective actions, such as instructions, reprimands, warnings, termination of actions / activities, investigation or in-depth examination, and the imposition of minor sanctions up to weight. These corrective actions must be based on the contents of each standard that has been set.

\section{Leadership}

Universitas Pasifik Morotai (UNIPAS) has an organizational structure consisting of the University Senate; Leader of University; Faculty, study program, Research Institute and Community Service (LPPM) Bureau; Technical implementation Unit; and the Quality Assurance Agency (LPM). The faculties in the Universitas Pasifik Morotai (UNIPAS) consists of:

1. Faculty of Social and Political Sciences (Department of Public Administration)

2. Faculty of Economics (Accounting Study Program)

3. Faculty of Teacher Training and Education (PGSD Study Program and English Study Program)

4. Faculty of Marine Sciences (Study Program of Marine Sciences and Catching Technology Study Program)

5. Faculty of Mathematics and Natural Sciences (Mathematics Study Program)

6. Faculty of Engineering (Civil Engineering Study Program, Informatics Engineering Study Program, Industrial Engineering Study Program, and Environmental Engineering Study Program.

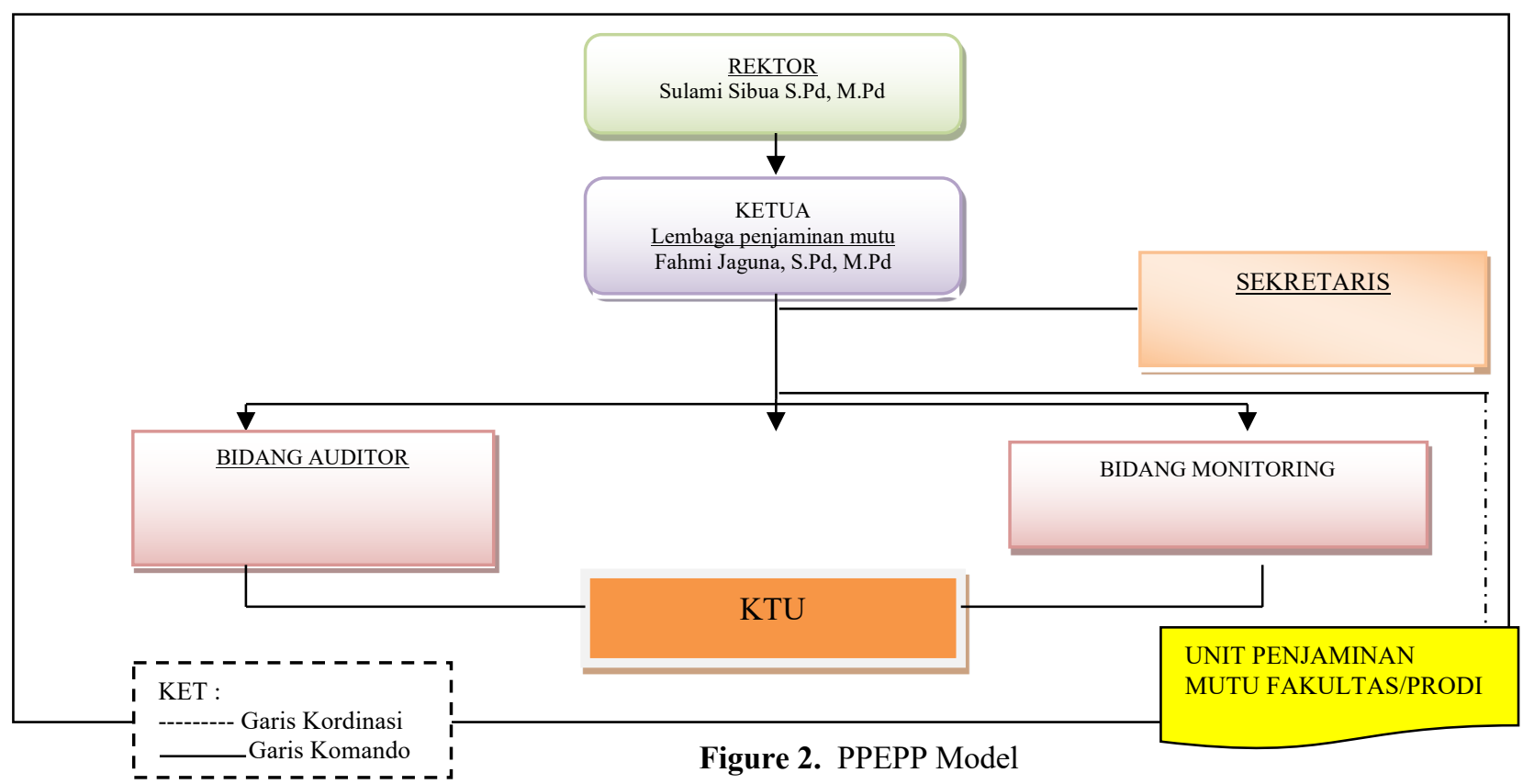




\section{Policy}

Implementation of quality standards includes the implementation and fulfillment of quality standards, complemented by monitoring and evaluation and internal audit activities. The results of internal monitoring and evaluation as well as internal audits are used to make corrections in the interest of improving quality standards. Development or improvement of quality standards is an effort to evaluate and improve the quality of the contents of the standard periodically and continuously. Standard evaluation is the act of evaluating the contents of a standard based, inter alia, on (a) the results of the implementation of the standard content in a previous time; (b) the development of the situation and condition of the university, the demands of the needs of university stakeholders and society in general, and (c) their relevance to the university's vision and mission. This will end with the setting of a new quality standard as an improvement from the previous standard.
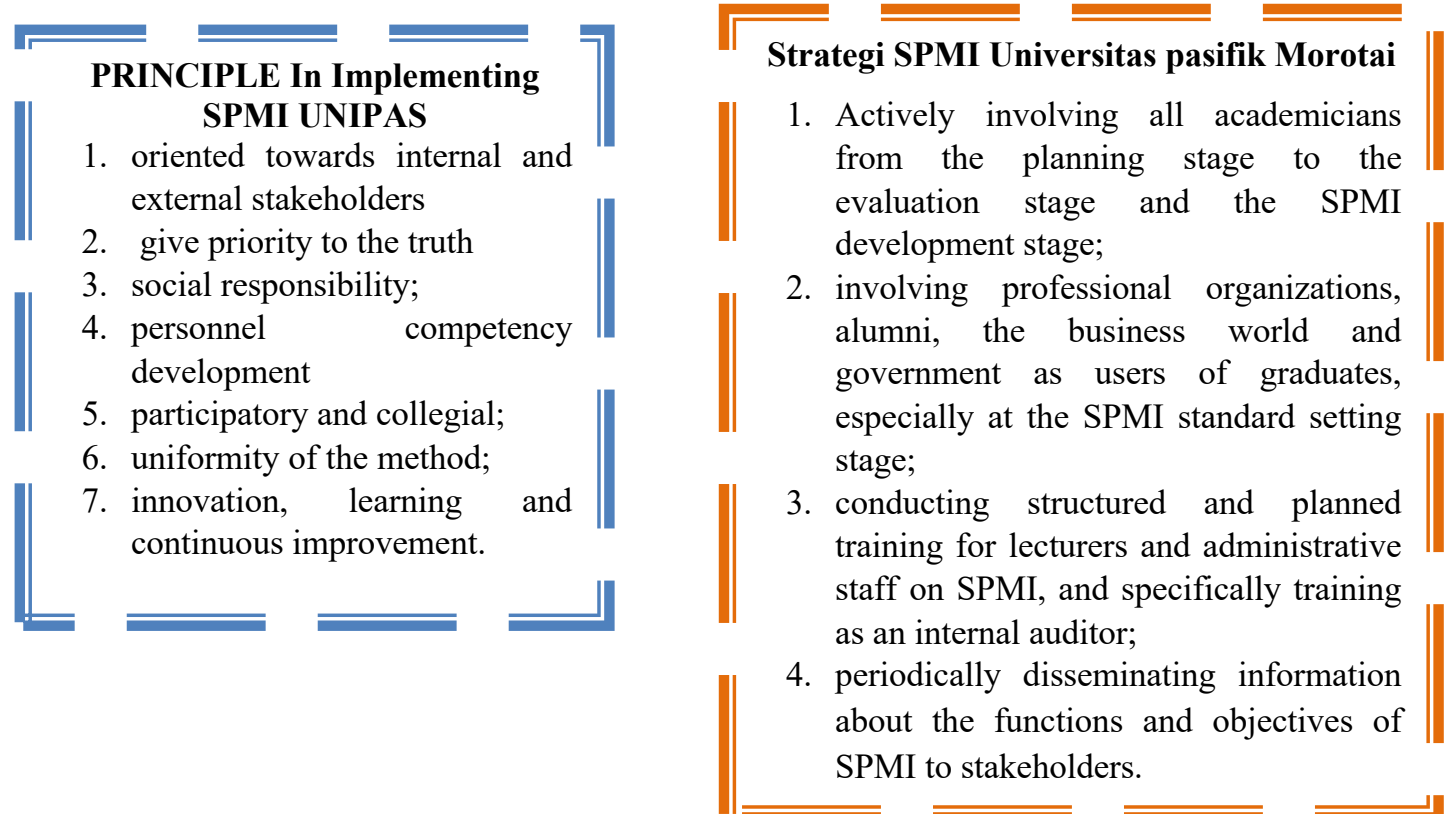

Figure 3. Quality Assurance

The Universitas Pasifik Morotai (UNIPAS) quality assurance system is carried out both in the academic field (education, research, and community service) and in the nonacademic field (administration and management of tertiary institutions).

1. The Chancellor is the person in charge of quality assurance at the university level, the dean responsible for quality assurance at the faculty level, and the head of the department / study program is the person responsible for quality assurance at the department / study program level

2. The Chairperson of the Quality Assurance Agency (LPM) is the coordinator of the quality assurance at the university level with the scope of work including coordination in both the academic and non-academic fields

3. Internal Quality Assurance Agency:

a. reviewing and formulating quality policies, quality manuals, quality standards, procedure manuals, forms / forms 
b. reviewing the results of internal quality audit evaluations and recommending improvements to the quality assurance system

c. get an explanation from individuals or work units in their environment related to meeting quality objectives, both in the academic and non-academic fields

d. gathering information from various sources about various matters relating to improving knowledge and implementing quality management of tertiary institutions

e. make a report of quality achievement on an ongoing basis.

\section{Planning}

The Universitas Pasifik Morotai (UNIPAS) Internal Quality Assurance System (SPMI) is a quality assurance system that is in accordance with the vision and mission on a regular basis to strive for continuous quality improvement. SPMI Universitas Pasifik Morotai (UNIPAS) was held to meet stakeholder satisfaction and in an effort to maintain accountability in the administration of tertiary education. To implement the SPMI Universitas Pasifik Morotai (UNIPAS), Standard Operating Procedures (SOP) are made so that all work units in the Universitas Pasifik Morotai (UNIPAS) environment are complied with. The step starts by establishing the SPMI Policy, Quality Manual, Quality Standards and Forms, as the management system in implementing. System

The main strategic way to achieve the goals of the Pacific University is

1. Improving the quality and development of education / teaching,

2. Improving the quality of research and community service,

3. Improving the quality of student affairs,

4. Improving the quality of institutions and cooperation

The main formulation of strategies to achieve the Universitas Pasifik Morotai (UNIPAS) goals, is further elaborated in the form of an education quality improvement program. The development program in detail is described as follows

1. Increasing access and quality of prospective students

2. Improving the quality of study programs

3. Improvement of student / lecturer ratio

4. Improvement of facilities and infrastructure

5. Procurement and Development of laboratory infrastructure

6. Improved information systems for academic services

7. Improving the quality of lecturers

In order to realize the Universitas Pasifik Morotai (UNIPAS) vision, a gradual and directed program of improvement or activities is carried out with clear and measurable performance indicators. Performance indicators are based on previous years' experience. Of course the ideal indicators and measurements do not have to be achieved in the 2013-2017 period because it is very dependent on the performance that has been achieved. In accordance with the direction or development program to improve the quality of Universitas Pasifik Morotai (UNIPAS) education, the following are several indicators used to assess the achievement of development programs as follows:

1. Tight quality of new students

2. Number of accredited study programs

3. Student lecturer ratio

4. Lecture / student room ratio

5. Laboratory / student ratio

6. Percent of lecturers holding master degrees 
7. Lecture / student room ratio

8. Certification of lecturers and education staff

\section{CONCLUSIONS}

Quality management is a value, mental attitude, a system, as well as a pattern of activities where the management of a tertiary institution is directed consciously, systematically, and efficiently to achieve stakeholder satisfaction and increase in value. Whereas quality assurance is a process, mechanism, and procedure to guarantee that quality management will truly be carried out in accordance with the standards, norms, demands, and satisfaction of stakeholders.

Universitas Pasifik Morotai (UNIPAS)'s Internal Quality Management System (SPMI) as a criterion, measure, or benchmark for all higher education implementation activities to realize its vision and mission so that it can be assessed as quality according to statutory provisions so as to satisfy internal and external stakeholders. Quality Standards in SPMI Universitas Pasifik Morotai (UNIPAS) refers to National Education Standards and other relevant standards. The quality standard consists of quality standards for the implementation of Tri Dharma Higher Education activities.

The SPMI management model at the Universitas Pasifik Morotai (UNIPAS) based on PPEPP (Planning, Implementation, Evaluation, Improvement) will produce kaizen or Continuous quality improvement of higher education quality. Performance on LPM already has their respective duties but all decisions are taken based on the approval of the chancellor. Policies in SPMI at Universitas Pasifik Morotai (UNIPAS): 1) actively involve all academicians from the planning stage to the evaluation stage and the SPMI development stage; 2) involving professional organizations, alumni, the business world and government as users of graduates, especially at the SPMI standard setting stage; 3 ) conduct structured and planned training for lecturers and administrative staff on SPMI, and specifically training as an internal auditor; and 4) periodically disseminating information about the functions and objectives of SPMI to stakeholders. To implement the SPMI Universitas Pasifik Morotai (UNIPAS), Standard Operating Procedures (SOP) are made to be obeyed by all work units in the Universitas Pasifik Morotai (UNIPAS) environment.

\section{REFERENCE}

Dokumen Mutu Universitas Pasifik Morotai

Fakry Gafar. 2020. Interconnection. Upi. Edu

Gamage, D. T., \& Zajda, J. (2005). Decentralization and school-based management: A comparative study of self-governing schools models. Educational Practice and Theory, 27(2), 35-58.

Hughes Et Al. (2002)-Mapping in Police Agencies. https://www.scribd. com/document/111877268/Hughes-Et-Al-2002-Mapping-in-Police-Agencies

Handoko, 2003. Manajemen Personalia dan Sumber Daya Manusia. Yogyakarta: BPFE Marjali Amri. 2007. Manajemen Mutu Akademik Universitas Indonesia.

Rawita, Sutisno. 2013. Kebijakan Pendidikan Teori, implimentasi dan monev. Yogyakarta: Semesta 
Tony Bush. 2008. Leadership and Management Development In Education: Sage PublicationUsman, Husaini. 2014. Manajemen Teori, Praktik, dan Riset Pendidikan. Jakarta: Bumi Aksara 